\title{
Experimental study on atomization characteristics and dust- reduction performance of four common types of pressure nozzles in underground coal mines
}

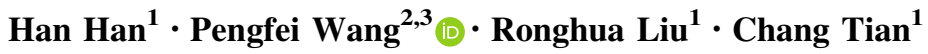

Received: 12 October 2019/Revised: 20 April 2020/Accepted: 11 May 2020/Published online: 27 May 2020

(C) The Author(s) 2020

\begin{abstract}
Pressure nozzle is commonly used in the dust-reduction techniques by spraying of underground coal mines. Based on the internal structure, the pressure nozzle can be divided into the following types: spiral channel nozzle, tangential flow-guided nozzle and X-swirl nozzle. In order to provide better guidance on the selection of nozzles for the coal mine dust-reduction systems by spraying, we designed comparing experiments to study the atomization characteristics and dust-reduction performance of four commonly used nozzles in the coal mine underground with different internal structures. From the experimental results on the atomization characteristics, both the tangential flow-guided nozzle and the $\mathrm{X}$-swirl nozzle have high flow coefficients. The atomization angle is the largest in the spiral non-porous nozzle, and smallest in both the X-swirl nozzle and the spiral porous nozzle. The spraying range and the droplet velocity are inversely proportional to the atomization angle. When the water pressure is low, the atomization performance of the spiral nonporous nozzle is the best among the four types of nozzles. The atomization performance of the $\mathrm{X}$-swirl nozzle is superior to other types when the water pressure is high. Under the high water pressure, the particle size of the atomized droplets is smallest in the X-swirl nozzle. Through the experiments on the dust-reduction performance of the four types of nozzles and the comprehensive analysis, the X-swirl nozzle is recommended for the coal mine application site with low water pressure in the dust-reduction system, while at the sites with high water pressure, the spiral non-porous nozzle is recommended, which has the lowest water consumption and obvious economic advantages.
\end{abstract}

Keywords Pressure nozzle $\cdot$ Atomization characteristics $\cdot$ Dust-reduction performance $\cdot$ Droplets $\cdot$ Dust

Pengfei Wang

pfwang@sina.cn

1 Work Safety Key Lab on Prevention and Control of Gas and Roof Disasters for Southern Coal Mines, Hunan University of Science and Technology, Xiangtan 411201, China

2 School of Resource Environment and Safety Engineering, Hunan University of Science and Technology, Xiangtan 411201, China

3 Department of Civil and Architectural Engineering and Mechanic, University of Arizona, Tucson, AZ 85721, USA

\section{Introduction}

A large amount of dust is generated in the coal mine production fields such as mining, tunneling, transport, etc. (Wang et al. 2019; Luo et al. 2017). The health condition and life safety of the coal mine workers, who work in the environments with high-concentration dust for a long time, are seriously threatened (Zhang et al. 2018; Reed et al. 2018; Zhou et al. 2017). At present, the spraying technology for dust reduction has been widely applied in coal mine underground because of its simple assembly, easy operation, and strong applicability (Yang et al. 2019; Wang et al. 2018a). The atomizing nozzle is a key component of the spraying system for dust reduction. According to the atomization principle, the commonly used atomizing 
nozzle can be divided into different categories, i.e., pressure nozzle, rotary nozzle, pneumatic nozzle and ultrasonic nozzle. Among all the types of nozzles, the pressure atomizing nozzle is widely used in the dust reduction by spraying due to its simple structure and strong adaptability (Wang et al. 2018b, 2020).

The dust-reduction performance of the pressure nozzle is closely related to the atomization effect and the particle size of the droplets is an important indicator to evaluate the atomization effect of the nozzle. Some researchers studied the maximum entropy model and proposed a new method to predict the size distribution of droplets using the maximum entropy model (Sellens 1989; Li and Tankin 1992; Dumouchel 2009). Wang and Lefebvre (1987) and Couto et al. (1997) established a theoretical equation to calculate the SMD of pressure swirl nozzle based on the hypothesis on the fracture thickness of the liquid film. In addition, based the finite volume VOF method, there have been a large amount of studies on the internal flow field and atomization characteristics of pressure nozzles using numerical simulations (Fan et al. 2018; Zhao and He 2017; Chen and Ge 2013). Cheng et al. (2010) and Zhou et al. (2012) studied the atomization characteristics of the tangential flow-guide nozzle pressure nozzle by experiment, which was commonly used in coal mines, and obtained the relationship between the particle size of atomized droplets and the water pressure. Yi et al. (2018) measured the atomization angle of the $\mathrm{X}$-swirl pressure nozzle, and obtained the formula for calculating the atomization angle of the nozzle by fitting. Nie et al. (2017) compared the atomization characteristics of two common pressure nozzles, spiral channel type and X-swirl type, and found that the spiral channel type pressure nozzle has a large atomization angle, but the range is short. At the same time, because the internal structure of the nozzle has an important influence on the atomization characteristics, Seoksu et al. $(2008,2009)$ studied the inclination angle and flow angle of the swirl nozzle, and concluded that when the inclination angle is large, an air core is formed and during the flow atomization, backflow vortex occurs. Harshad et al. (2020) selected three solid-cone nozzles with X-type swirl-insert and orifice diameters of 1.65, 1.90, and $2.45 \mathrm{~mm}$ to study the discharge coefficient, spray cone angle and mass flux density in the spray, and the size distribution of droplets, and finally fit the distribution formula of the same kind of nozzle spray characteristics.

Based on the studies on the atomization characteristics, some researchers have worked on the theoretical analysis on the dust-reduction by spray from pressure nozzles. Ma and Kou $(2005,2006)$ established a mathematical dustreduction model by high-pressure spray and obtained a theoretical calculation equation of classification efficiency using the fluid mechanics and aerosol theories. Cheng et al.
(2011) analyzed the dust-reduction mechanism by highpressure spray, investigated the effect of water pressure on the dust-reduction efficiency by spraying, and proposed the calculation equation of minimum particle size in the dust collection by the atomized droplet. Based on the momentum and mass conservation equations of droplets and dust, Tawatchi and Wiwut (2011)established a prediction model for the dust inertia-interception efficiency in the dust reduction by spraying water droplets in open space. In addition, the authors verified the accuracy of the model by experimental results. Yu et al. (2018) established a mathematical model of gas-liquid-solid three-phase coupling and verified the validity of the mathematical model. The mathematical model has been applied to predict the dustreduction efficiency of the pressure nozzle in the fully mechanized mining face and obtained accurate prediction in the application.

The pressure nozzles commonly used in coal mine production sites for dust reduction by spraying can be roughly classified into different categories according to internal structure, including spiral channel nozzle, tangential flow-guide nozzle, X-swirl nozzle. The spiral channel nozzle can be further divided into two types, i.e., spiral porous nozzle and spiral non-porous nozzle. The spraying flow of the above nozzles has solid conical shapes. Due to the differences in the internal structure of the nozzles, the atomization characteristics and dust-reduction performance of the above nozzles are different. In addition, the applicable conditions of different types of nozzle are also different. In the coal mine application site, the design of the dust-reduction scheme and the selection of the nozzle should be dependent on the actual application conditions, including the water consumption requirement of nozzles and the water pressure in the pipe network. By comprehensive considerations on these conditions, an economical and rational dust-reduction scheme can be obtained. Most of the existing studies on the pressure nozzles focused on the analysis of single-structure nozzles. However, there are only few studies to compare the atomization characteristics and the dust-reduction performance of several common types of pressure nozzles. As a result, the design of dust reduction system and the selection of spray nozzles in coal mine applications have challenges. In this study, a custom-developed dust-reduction test platform was used to systematically compare the atomization characteristics and dust-reduction performance of the above-mentioned four different types of nozzles. The results in this study can provide reference for the design of dust-reduction scheme by spraying and the selection of nozzles in coal mine applications. 


\section{Experimental system and scheme}

\subsection{Selection of nozzles}

According to the previous on-site investigation, four pressure nozzles which are commonly used in coal mine fields were analyzed in this study, i.e., the tangential flow-guide nozzle, the X-swirl nozzle, the spiral porous nozzle, and the spiral non-porous nozzle. Among them, the tangential flow nozzle has three internal vertical channels at the center of the nozzle. The interior of the X-swirl nozzle is an $\mathrm{X}$-shaped water flow channel. The inside of the spiral porous nozzle is composed of a spiral channel around and a vertical channel in the middle, while the spiral non-porous nozzle has no intermediate channel. In coal mine production sites, the water used for dust-reduction generally contains impurities. In order to reduce clogging, the outlet diameter of nozzles cannot be too small. At the same time, for ensuring the atomization effect, the outlet diameter of nozzles should not be too large. Based on the comprehensive consideration, the outlet diameter of $1.2 \mathrm{~mm}$ is suitable for the nozzles in coal mine production sites (Wang et al. 2015). Therefore, the four different pressure nozzles selected in the experiment all had the outlet diameters $1.2 \mathrm{~mm}$. The pressure nozzles selected in the experiment are shown in Fig. 1.

\subsection{Experiment system}

An experimental system for dust reduction by spraying is shown in Fig. 2. The system can simulate the processes such as dust generation, spraying, ventilation, etc. in coal mine production sites. The experimental system contained roadway model, high-pressure water pump, water tank, control cabinet, aerosol generator, Malvern droplet size analyzer, particle image velocimetry (PIV) and related pipelines, valves, and measuring instruments. The roadway model consisted of an inlet section, a measurement section, a spraying section, an axial flow fan and an outlet section. In order to facilitate the data acquisition of the Malvern droplet size analyzer and PIV system, the main section of the roadway model is made of transparent plexiglass with a thickness of $1 \mathrm{~cm}$.

\subsection{Measuring instrument and scheme of atomization characteristic}

The atomization characteristics of nozzles include flow rate, atomization angle, range, droplet size, and droplet velocity. The water flow rate and water pressure of nozzles were measured using an electromagnetic flowmeter (YYLED15K4C) and a digital pressure gauge (DX801XB00150), respectively. A high-performance digital camera was used to capture the spraying field, and then Image-Pro Plus 6.0 post-processing software was used to calculate the atomization angle and the range. The Malvern droplet size analyzer was used to measure the particle size of the droplets in this experiment. However, the Malvern droplet size analyzer is unable to measure the droplet velocity of the flow field. In this experiment, the PIV system produced by LaVision, Germany was used to measure the droplet velocity. Figure 3 shows the equipment used in the atomization characteristics experiment for nozzles.

The Malvern droplet particle size analyzer is based on the line-measurement principle. The particle size
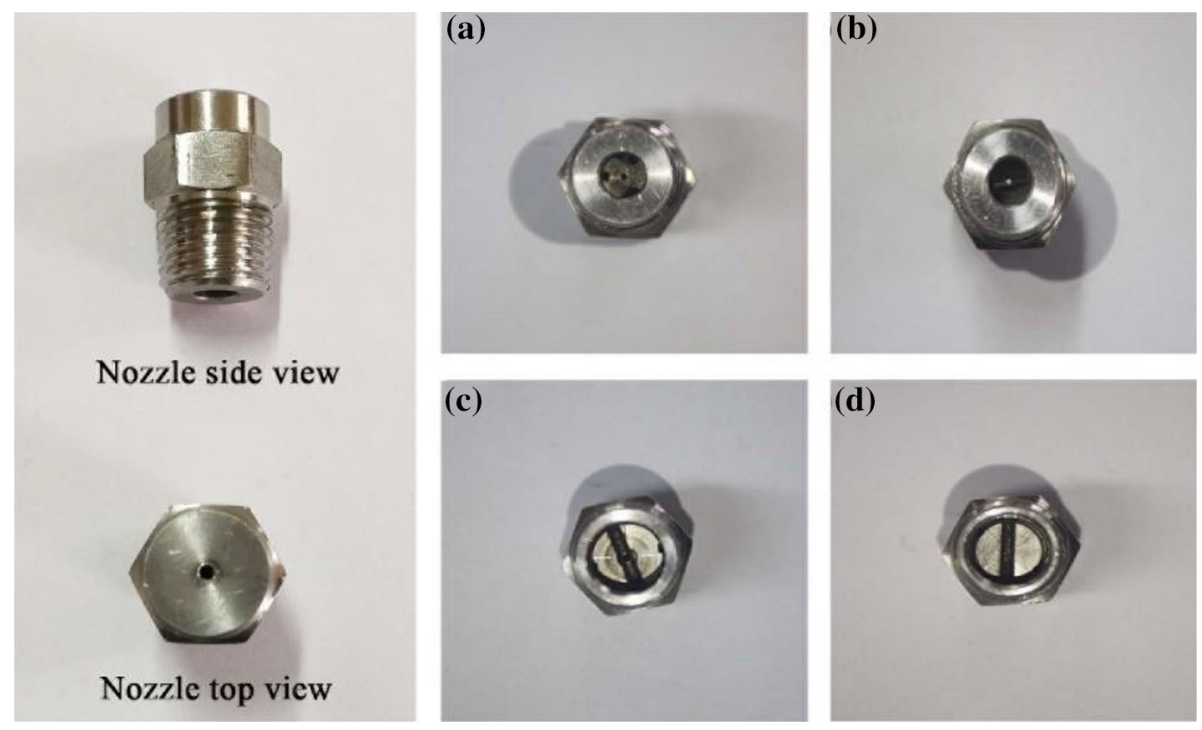

Fig. 1 Nozzles in the experiment. a Tangential flow-guide; b X-swirl; c Spiral porous; and d Spiral non-porous 


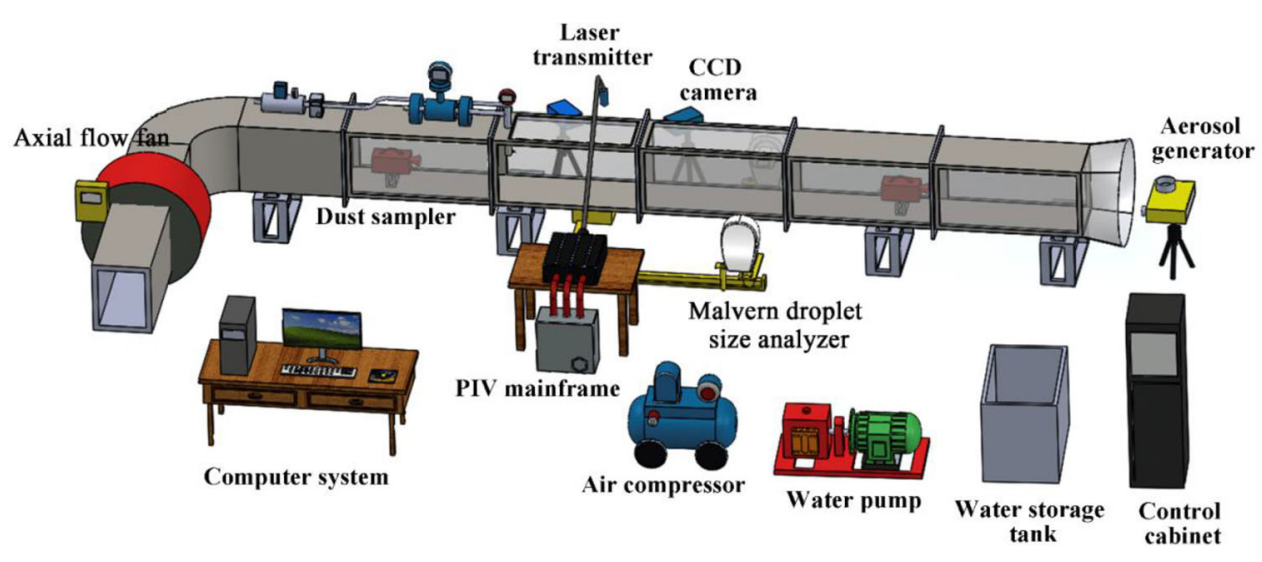

Fig. 2 Spray experimental system for dust reduction
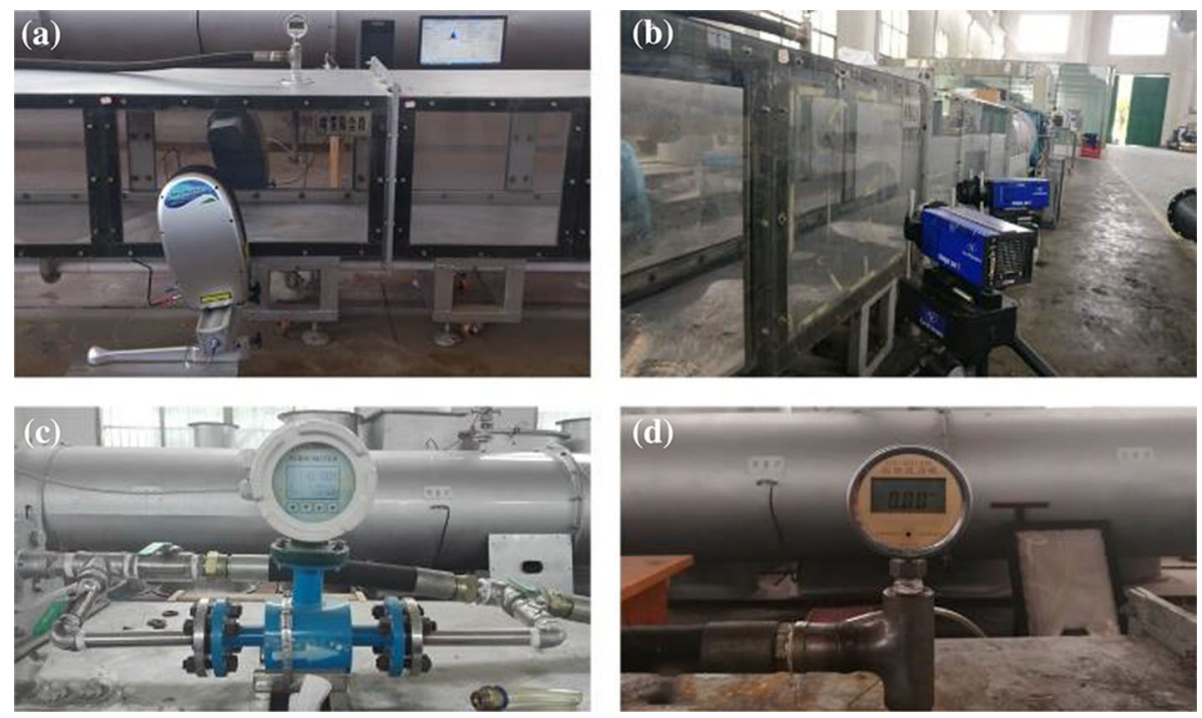

Fig. 3 Measuring instruments for nozzle atomization characteristics analysis. a Malvern droplet size analyzer; b PIV; c YY-LED15K4C electromagnetic flowmeter; and d DX-801XB digital pressure meter

distribution of the droplets along the laser beam line was measured. The area which was $50 \mathrm{~cm}$ in front of the nozzle exit was selected for the data acquisition of particle size. At the same time, the water pressure of the nozzle in this experiment was set to 1.0-8.0 MPa based on the actual conditions of the industrial application. The PIV system captured the flow field in the area of 30-80 cm in front of the nozzle and the capturing range was $50 \mathrm{~cm} \times 50 \mathrm{~cm}$. In this PIV experiment, the exposure interval $\mathrm{d} t$ was set to $300 \mu$ s, and the power of light source A and B were set to $50 \%$ and $45 \%$ of the maximum power respectively. In each PIV test, 20 groups of double frame photos were obtained from CCD cameras, and then the flow field of the twenty groups of double frame photos was analyzed to produce a velocity profile. The high water pressure can cause excessive concentration of the droplets in the downstream flow field, which affects the tracing capability of particles and reduces the measurement accuracy. Therefore, in the
PIV experiment, only three lower water pressures were used for analysis, i.e., 1.0, 2.0, and 3.0 MPa, respectively.

\subsection{Measuring instrument and scheme of dust- reduction performance of nozzles}

In the experiments of dust-reduction performance, the German AG420 aerosol generator was used to generate dust and the compressed air provided by the air compressor was used as the transmission power for the dust. The dust was sent into the roadway from the entrance to simulate the production of dust in the industrial fields. Two explosionproof dust samplers (FCC-25) were arranged in the measurement section in the model roadway, i.e., one before the spraying section and one after the spraying sections. The dust in the two areas, i.e., before and after spraying was sampled under different working conditions. The dust in 
the two measuring points was sampled at the same time. At each measuring point, three continuous measurements were collected to obtain the average value for each working condition. The filter membranes of dust before and after sampling were weighed by an electronic analytical balance, and total dust mass concentration $c_{\mathrm{mt}}$ and the total dust reduction efficiency $\eta_{\mathrm{t}}$ were calculated. The LS13320 laser particle size analyzer was used to analyze the particle size of the collected dust samples. The proportions of respirable dust before and after spraying were obtained. Then mass concentration of respirable dust $c_{\mathrm{mr}}$ and dust reduction efficiency of respirable dust $\eta_{\mathrm{r}}$ were obtained by combining the proportion of respirable dust with the total dust mass concentration $c_{\mathrm{mt}}$ (Wang et al. 2020). The equipment used for measuring the dust-reduction performance of the nozzle is shown in Fig. 4.

The dust-reduction efficiency by spraying using the four nozzles at three water pressures: 2.0, 4.0 and 6.0 MPa, was measured. The dust in the experiment was a coal powder with the particle size of less than $106 \mu \mathrm{m}$, which was selected by more than 150 standard industrial fields. The dust generation by AG420 aerosol generator was set to be $15 \mathrm{~g} / \mathrm{min}$ and the delivery pressure was set to be $0.2 \mathrm{MPa}$. The sampling duration of the FCC-25 dust sampler was set to $2 \mathrm{~min}$ and the sampling flow rate was set to be $15 \mathrm{~L} / \mathrm{min}$. Through the frequency modulation of the axial flow fan, the air flow velocity in the model roadway was stabilized at $1.0 \mathrm{~m} / \mathrm{s}$.

\section{Experimental results and analysis on atomization characteristics of nozzles}

\subsection{Flow rate of nozzle}

Based on the relevant data, the following relationship between the flow rate of pressure nozzles and the water pressure was obtained (Wang et al. 2018b).

$Q=\frac{\pi}{4} C_{\mathrm{q}} d^{2} \sqrt{\frac{2 p}{\rho}} \times 10^{-3}$

where $Q$ is the flow rate of the nozzle in the unit of $\mathrm{m}^{3} / \mathrm{s}, C_{\mathrm{q}}$ is the flow coefficient, $d$ is the outlet diameter of the nozzle in the unit of mm, $p$ is the water pressure in the unit of MPa, $\rho$ is the liquid density in the unit of $\mathrm{kg} / \mathrm{m}^{3}$. In Eq. (1), $d=1.2 \mathrm{~mm}$ and $\rho=1000 \mathrm{~kg} / \mathrm{m}^{3}$. The flow rates of the four types of nozzles were measured under different water pressures. In addition, the fitting analysis on the measured data was conducted using SPSS software based on the above equation. The flow coefficients of the four types of nozzles are shown in Table 1.

According to the analysis of the data in Table 1, the flow rates of the four types of nozzles all gradually increase as the water pressure increases. At the same time, the flow coefficient of the two types of spiral channel nozzles is small, while the flow coefficients of the tangential flowguide nozzle and the $\mathrm{X}$-swirl nozzle are similar. For the spiral channel nozzle, the effective flow-through area
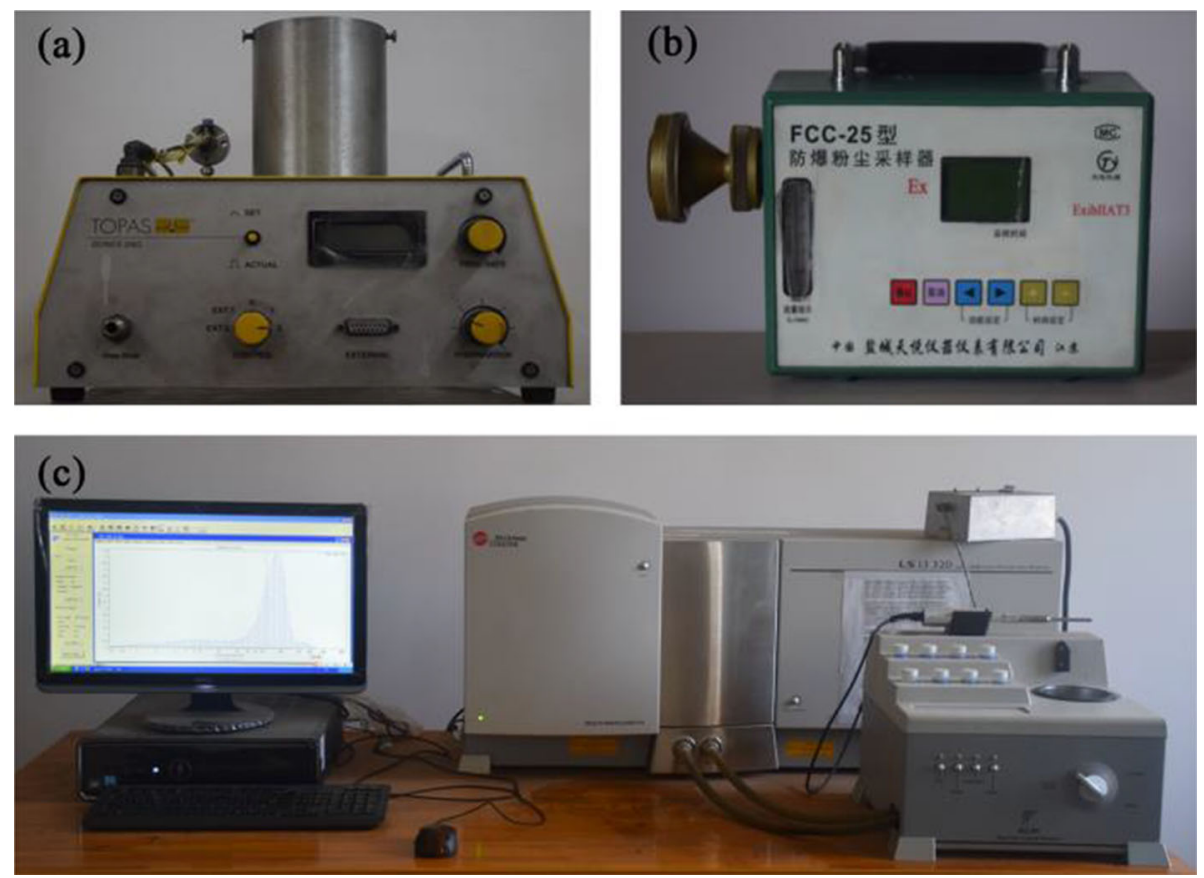

Fig. 4 Measuring instrument for dust reduction performance. a Aerosol generator, AG420; b Explosion-proof dust sampler, FCC-25; and c Laser particle size analyzer, LS13320 
Table 1 Relationship between flow rates of four nozzle and water pressure

\begin{tabular}{llllllllll}
\hline Type & \multicolumn{2}{l}{$Q(\mathrm{~L} / \mathrm{min})$} & & & & \multicolumn{1}{c}{$C_{\mathrm{q}}$} \\
\cline { 2 - 7 } & $1 \mathrm{MPa}$ & $2 \mathrm{MPa}$ & $3 \mathrm{MPa}$ & $4 \mathrm{MPa}$ & $5 \mathrm{MPa}$ & $6 \mathrm{MPa}$ & $7 \mathrm{MPa}$ & $8 \mathrm{MPa}$ \\
\hline Tangential flow-guide & 2.33 & 3.50 & 3.83 & 4.50 & 5.33 & 6.00 & 6.17 & 6.83 & 0.611 \\
X-swirl nozzle & 2.33 & 2.83 & 3.67 & 4.17 & 5.50 & 5.83 & 6.33 & 6.83 & 0.604 \\
Spiral porous & 2.50 & 3.17 & 3.83 & 4.17 & 5.17 & 5.33 & 5.67 & 6.17 & 0.564 \\
Spiral non-porous & 1.83 & 2.33 & 2.83 & 3.17 & 3.83 & 4.17 & 4.33 & 4.83 & 0.432 \\
\hline
\end{tabular}

inside the nozzle is small and the internal resistance of the nozzle is large, thus the flow rate is small at the same water pressure and outlet diameter. The spiral porous nozzle has a flow passage in the middle, which greatly reduces the flow resistance, resulting in a larger flow coefficient than that of the spiral non-porous nozzle. Since the internal flow-through areas of the tangential flow-guide nozzle and the X-swirl type are relatively large, the internal resistance is relatively small and results in a larger flow coefficient than that of the spiral channel nozzle. The dust reduction efficiency by spraying is closely related to the water amount. The nozzle with large flow coefficient can increase the atomized water amount per unit volume under the same water pressure, which is beneficial to improve the dustreduction efficiency.

\subsection{Atomization angle and range}

The atomization angle and range are two important parameters of atomization characteristics, which determine the effective effect area of the spraying flow field of the nozzle. The larger the atomization angle is, the wider the coverage area by the atomized flow is. The wider coverage area can reduce the number of installed nozzle and the larger range of nozzles can achieve long-distance dust-reduction. Figure 5 shows the atomization angle and range of four types of nozzles under different water pressures.

Figure 5a shows the measured data of the atomization angle. From Fig. 5a, it can be seen that with the increase of the water pressure, the atomization angle $\alpha$ of the four types of nozzles first increases and then decreases. Figure 6 is a photograph of the spraying field under the corresponding working conditions, which shows the same trend of atomization angle with the change of water pressure. When the water pressure increases, the flow rate increases accordingly, resulting in the increases of both the swirling force inside the nozzle and the radial velocity of the outlet jet from the nozzle. As a result, the atomization angle increases as the water pressure increases. When the water pressure is higher than 6.0 $\mathrm{MPa}$, there is a negative pressure in the center of the rotary droplet flow at the nozzle outlet. The higher the water pressure is, the more obvious the negative pressure effect is observed. The negative pressure effect causes the droplet flow to shrink toward the center, resulting in a smaller atomization angle.

From Figs. 5a and 6, it can be seen that the spiral nonporous nozzle has the largest atomization angle under the same water pressure and the smallest variation with the increase of the water pressure. The atomization angle of the spiral non-porous nozzle is always maintained at around $56^{\circ}$. For the spiral non-porous nozzle, the spiral channel design improves the flow intensity at the outlet. In addition, since there are no holes in the center of the spiral nonporous nozzle, the water flow is completely swirled along the spiral passage of the inner wall and then ejected from the nozzle outlet. The water flows swirled along the spiral passage has a large centrifugal force, which results in a large radial velocity at the nozzle outlet and a large atomization angle. For the tangential flow-guide nozzle, the spraying flow is introduced into the nozzle along the tangential direction, which also has a high swirling intensity, resulting in a relatively high atomization angle. For the $\mathrm{X}$-swirl nozzle, the X-shaped design of the inner core in the nozzle is not as beneficial to the swirling strength as the designs in the tangential flow-guide nozzle and the spiral non-porous nozzle. Thus the atomization angle of the $\mathrm{X}$-swirl nozzle is relatively small. The atomization angle of the spiral porous nozzle is relatively small because the flow was not swirled before being injected from the nozzle.

Figure $5 \mathrm{~b}$ shows the atomization range of the four types of nozzles under different water pressures. It can be seen that as the water pressure increases, the spraying range increases. For pressure nozzles, as the water pressure increases, the flow rate increases, resulting in the increase of spraying range. Among the four types of nozzles, the $\mathrm{X}$-swirl type and the tangential flow-guided type have relatively large range under the same water pressure. From the experimental results on the flow characteristics, the difference in the flow coefficients of the four types of nozzles was not significant, which indicated that the flow rate of the four types of nozzles was close under the same water pressure. When the flow rate is close, the range of the nozzle is inversely proportional to the atomization angle. Thus the nozzle with a larger atomization angle has a 

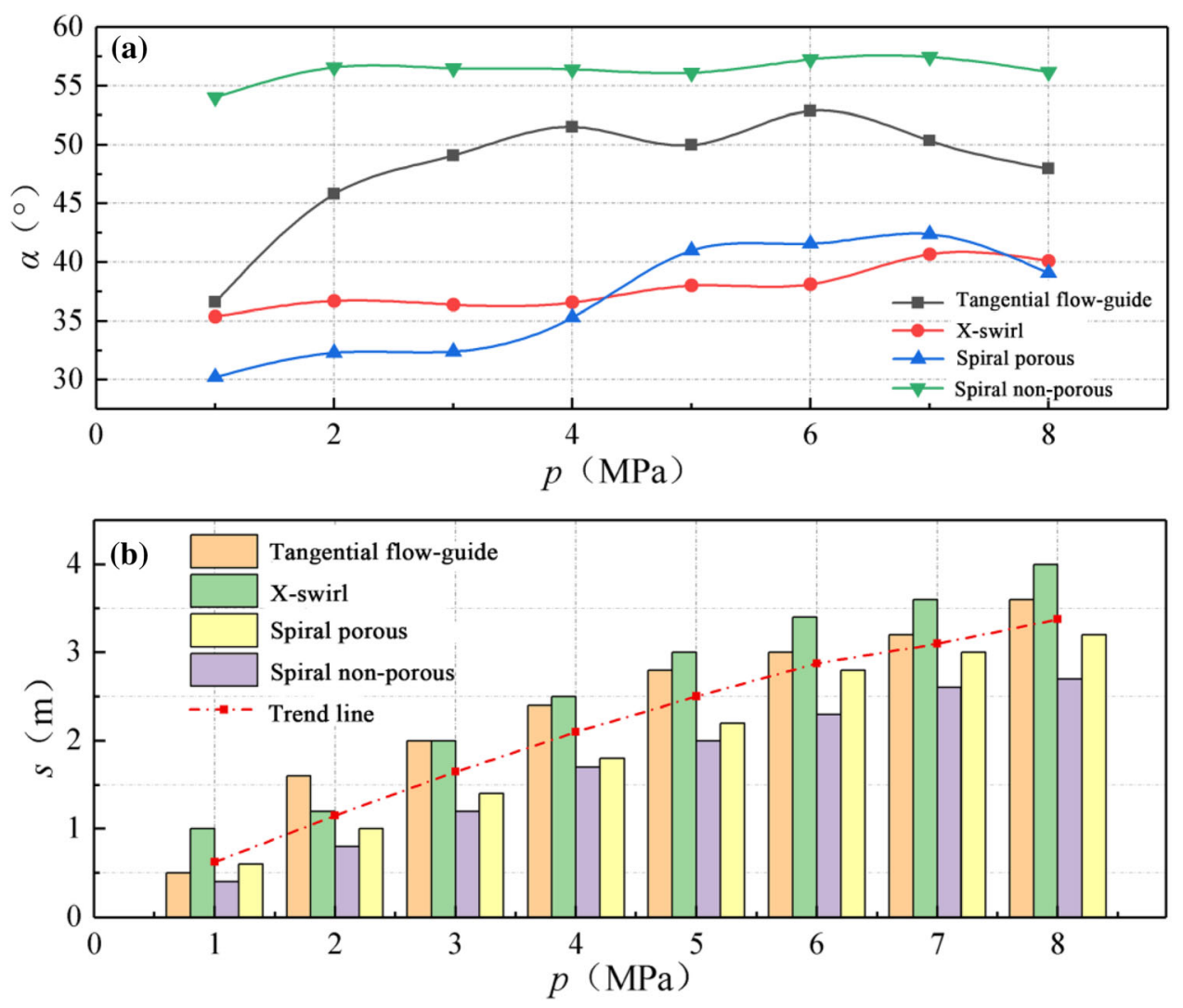

Fig. 5 Atomization angles and ranges of four nozzle. a Atomization angle; and b Range

relatively smaller range. X-swirl and tangential flow-guided nozzles have a smaller atomization angle and thus a relatively large range, while the other two types of nozzles have a smaller spray angle and a smaller range.

From the above analysis, the atomization angle and range of different types of nozzles vary due to the differences in the internal structural. Therefore, in the design of dust-reduction scheme by spraying in the engineering sites, the nozzle should be selected based on the performance. In the industrial sites where dust distribution is extensive and large-area dust reduction is required, such as the spray for hydraulic support in the fully-mechanized working face, spiral non-porous nozzles and tangential flow nozzles with large atomization angles can be selected. The flow coverage of the above two types of nozzles is large, which can save the number of installed nozzle. In the working environments that require long-distance dust reduction, such as the coal mine with dust reduction for shearers and roadheader, spiral-type or X-swirl nozzles should be selected. Both types of nozzles have a long range and can achieve long-distance dust reduction.

\subsection{Particle size of droplets}

Figure 7 shows the variation of the droplet size of four types of nozzles with the water pressure. In Fig. 7, $D_{10}$, $D_{50}$, and $D_{90}$ are characteristic particle diameters, respectively denoting that the particle volume of the particles less than it accounts for $10 \%, 50 \%$ and $90 \%$ of the total volume of the total particles.

Figure 7 indicates that as the water pressure increases, the characteristic parameters of the droplet size of the four types of nozzles all decrease. In addition, the change of the particle size in the low water pressure zone is more significant. As the water pressure increases, the Weber number of the pressure nozzle increases. As a result, the growth rate of the disturbing wave on the water jet surface increases, resulting in a smaller particle size of break-up and atomization. Figure 8 shows the droplet size distribution of the X-swirl nozzle under different water pressures. In Fig. 8, the solid red line represents the cumulative percentage of the droplet size, and the blue column represents the frequency of droplet volume. From the cumulative volume fraction curve in Fig. 8, the characteristic particle diameters $D_{90}, D_{50}$, and $D_{10}$ all exhibit the same trends as in Fig. 7. From the frequency histogram of the droplet volume in Fig. 8, when the water pressure is increased, the 
(a)

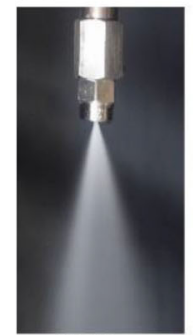

(b)

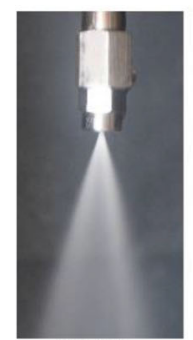

$1 \mathrm{MPa}$

(c)

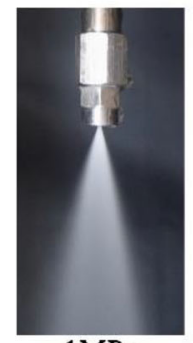

$1 \mathrm{MPa}$

(d)

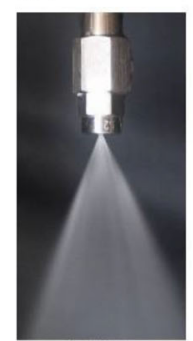

$1 \mathrm{MPa}$

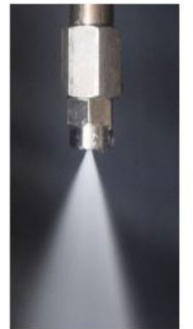

$2 \mathrm{MPa}$

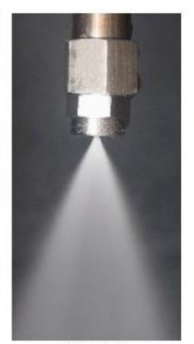

$2 \mathrm{MPa}$

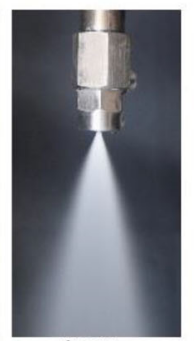

$2 \mathrm{MPa}$

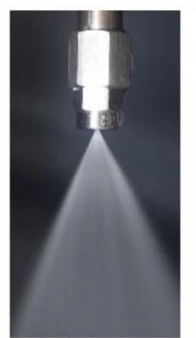

$2 \mathrm{MPa}$

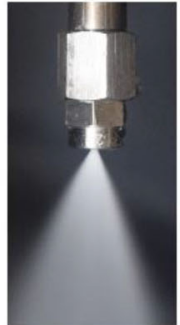

$3 \mathrm{MPa}$

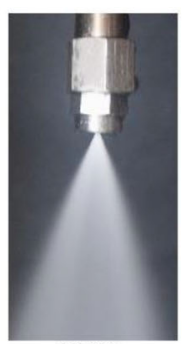

$3 \mathrm{MPa}$

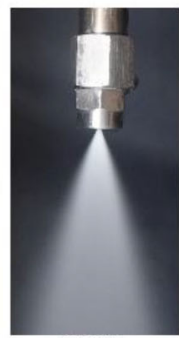

$3 \mathrm{MPa}$

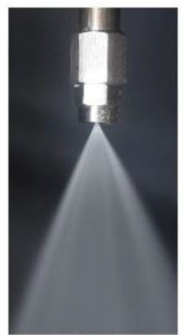

$3 \mathrm{MPa}$

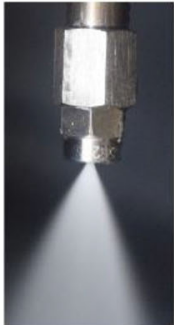

$4 \mathrm{MPa}$

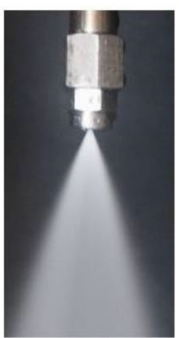

$4 \mathrm{MPa}$

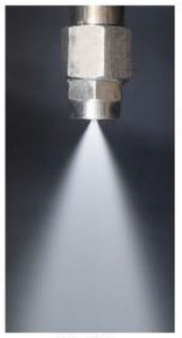

$4 \mathrm{MPa}$

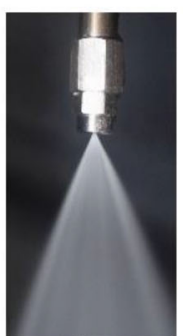

$4 \mathrm{MPa}$

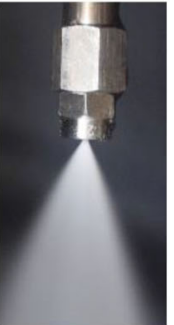

$5 \mathrm{MPa}$

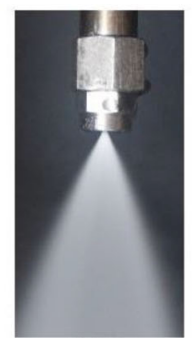

$5 \mathrm{MPa}$

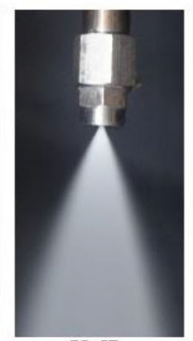

$5 \mathrm{MPa}$

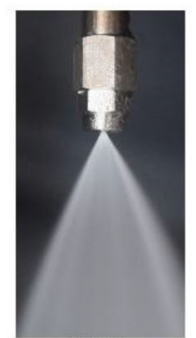

$5 \mathrm{MPa}$

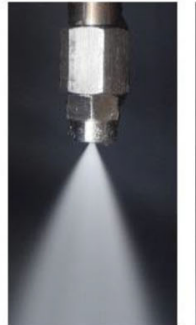

$6 \mathrm{MPa}$

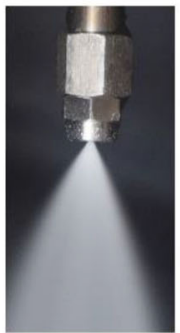

7MPa

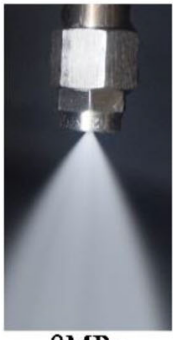

$8 \mathrm{MPa}$

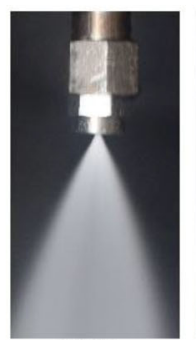

$6 \mathrm{MPa}$

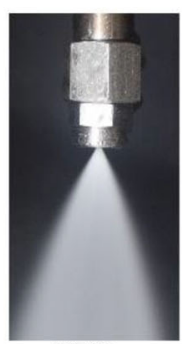

$7 \mathrm{MPa}$

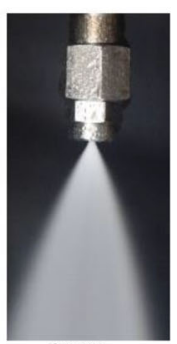

$8 \mathrm{MPa}$

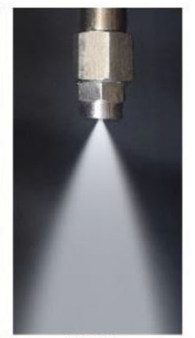

$6 \mathrm{MPa}$

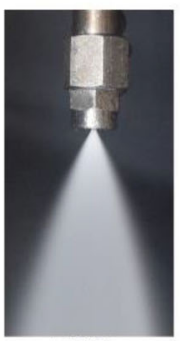

$7 \mathrm{MPa}$

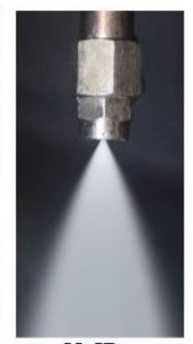

$8 \mathrm{MPa}$

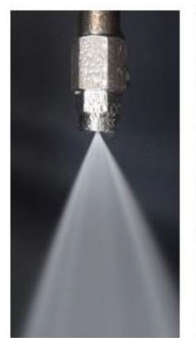

$6 \mathrm{MPa}$

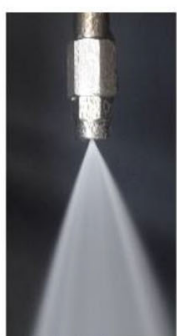

$7 \mathrm{MPa}$

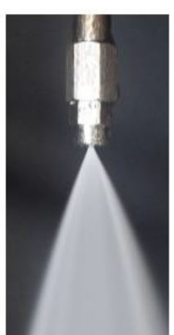

$8 \mathrm{MPa}$

Fig. 6 Photo of spray field under different working conditions. a Tangential flow-guide; b X-swirl; c Spiral porous; and d Spiral non-porous

peak frequency of the droplet volume is continuously shifted toward the left, i.e., toward the direction in which the droplet size decreases.

A comparative analysis on the curves in Fig. 7 reveals that the particle size exhibits different trend with the change of water pressure for four types of nozzles. Among the four types of nozzles, the spiral non-porous nozzle has the smallest variation of particle size. For instance, as the water pressure increases from 1.0 to $8.0 \mathrm{MPa}, D_{50}$ of the spiral non-porous nozzle is reduced from 112 to $85 \mu \mathrm{m}$ with a reduction ratio of less than $25 \%$, while $D_{50}$ of the other three types of nozzles are reduced by about or above $50 \%$. When the water pressure is low $(p<3 \mathrm{MPa})$, the spiral non-porous nozzle has the best atomization performance. In the high pressure zone, the X-swirl nozzle has advantages in the atomization performance, i.e., the smallest droplet size can be obtained from the X-swirl nozzle under the same water pressure. In general, the atomization performance of the tangential flow-guided nozzle is better than that of the spiral porous nozzle. Under the same water pressure, the $D_{50}$ from the tangential flowguided nozzle is smaller than that from the spiral porous 

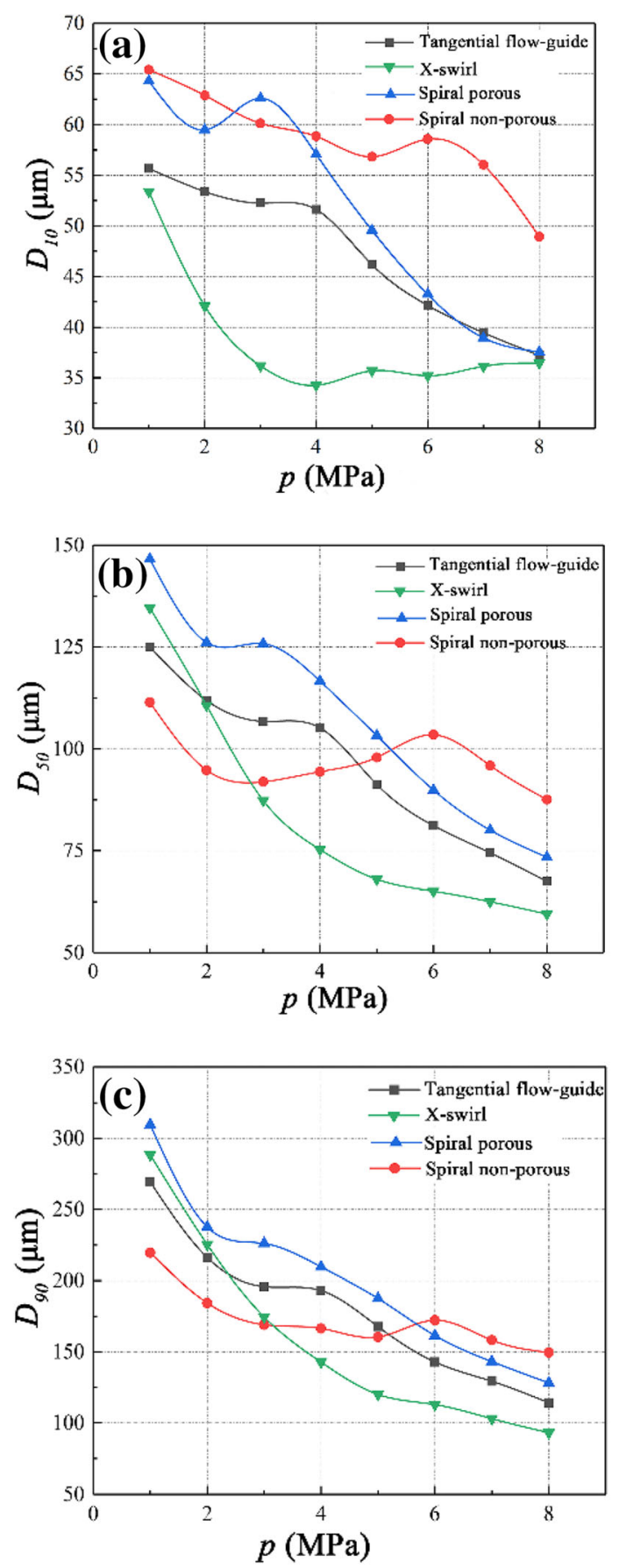

Fig. 7 Droplet size of the four types of nozzles under different water pressures. a $D_{10} ;$ b $D_{50}$; and c $D_{90}$

nozzle. The difference in atomization performance of the above four types of nozzles is caused by the different internal structure. The unique design of the swirling core in the X-swirl nozzle provides a better atomization performance, especially when the water pressure is high.

\subsection{Velocity of droplets}

The droplet velocity is an important indicator of the atomization performance of the nozzle. Under the same size, a higher relative velocity between dust and droplet is conducive to the deposition of dust, especially for respirable dust. The data of flow field measured by the PIV system was imported into Tecplot 360EX software and analyzed to obtain the vector diagram of the droplet velocity of the four types of nozzles under three water pressures, as shown in Fig. 9.

From the vector diagram of droplet velocity in Fig. 9, the droplet velocity in the downstream of the nozzle is continuously attenuated along the axial direction. The liquid is atomized to form droplets inside and outside the nozzle, and the droplet moves along the nozzle axis at a relatively high initial velocity. Due to the air resistance, the droplet velocity is continuously attenuated along the nozzle axis. Based on the comparison of the droplet velocities under different water pressures, the droplet velocity continuously increases as the water supply pressure increases. As the water supply pressure increases, the water flow rate of the nozzle increases continuously, thus the exiting velocity of the droplets from the nozzle is increased.

It is also shown in Fig. 9 that when the water pressure is the same, there is a large difference in the droplet velocity among the four types of nozzles. The smallest droplet velocity is observed in the spiral non-porous nozzle. From the experimental results of the flow characteristics, the spiral non-porous nozzle has a minimum flow coefficient and the smallest water flow rate under the same water pressure, resulting in the smallest exiting velocity. At the same time, the spiral non-porous nozzle has the largest atomization angle, and the droplet flow is dispersed after being emitted from the nozzle outlet. In addition, the speed is attenuated sharply due to the large air resistance of a single droplet. Moreover, under low water pressure, the atomization performance of the nozzle is superior and the average particle size of the droplets is small, thus the penetration ability of the small droplets is poor and the velocity decays sharply in the downstream of the nozzle. For the above reasons, the downstream speed of the spiral non-porous nozzle is significantly lower than that of the other three types of nozzles. The flow coefficients and outlet droplet velocity of other three types of nozzles are similar under the same water pressure. However, the spiral porous nozzle has the smallest atomization angle and the droplet flow is concentrated under low water pressure, resulting in a slow decay of the droplet velocity in the downstream and a high droplet velocity. The X-swirl nozzle has a higher atomization angle thus a higher droplet velocity than the tangential flow-guided nozzle. 

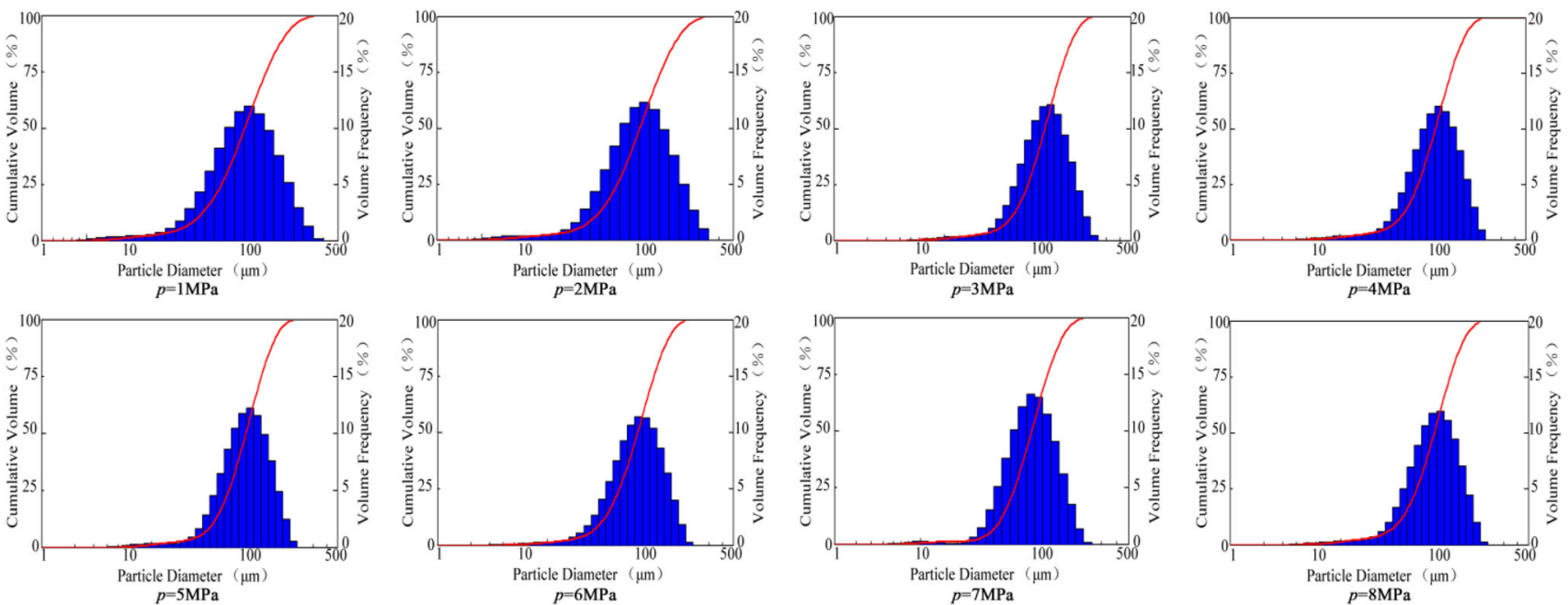

Fig. 8 Particle size distribution of X-swirl nozzle under different water pressures
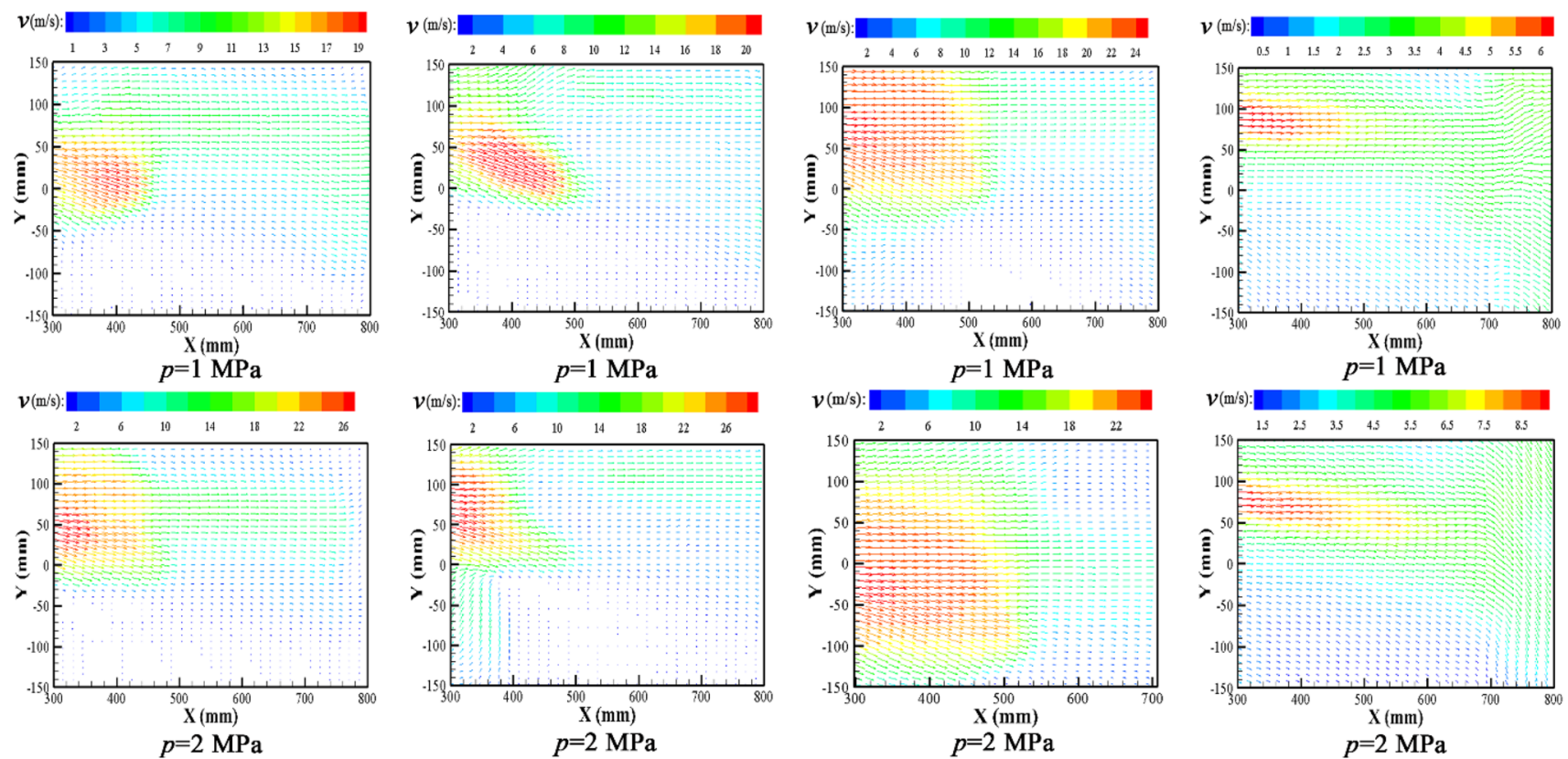

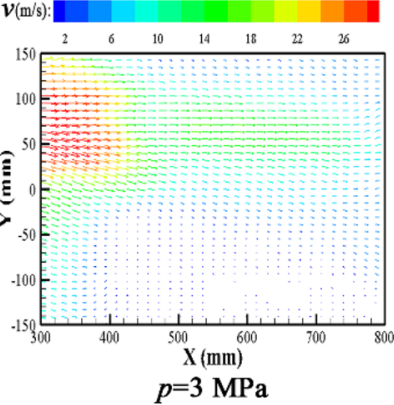

(a)

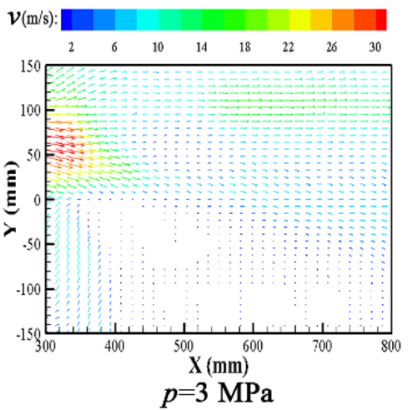

(b)

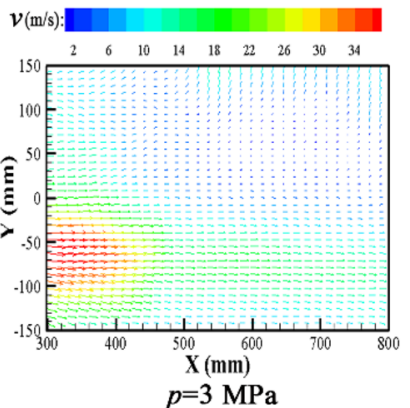

(c)

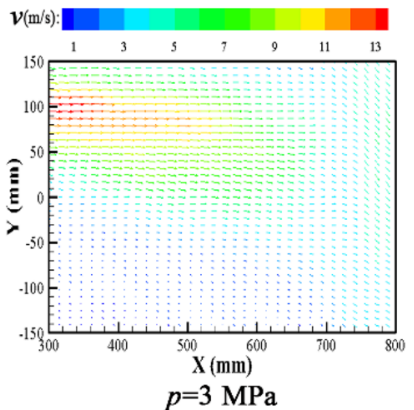

(d)

Fig. 9 Vector diagrams of droplet velocity in four nozzle droplet velocity. a Tangential flow-guide; b X-swirl; c Spiral porous; and d Spiral nonporous 
From the above analysis, under the similar flow coefficient, the atomization angle is the main factor affecting the droplet velocity in the downstream of the nozzle. Among the four types of nozzles, the spiral non-porous nozzle has the smallest flow coefficient and the largest atomization angle, thus having the smallest downstream droplet velocity. The droplet velocity of the other three types of nozzles is in the following order: spiral porous nozzle $>\mathrm{X}$ swirl nozzle $>$ tangential flow-guide nozzle.

\section{Experimental results and analysis on dust- reduction performance of nozzles}

\subsection{Mass concentration and particle size distribution of dust}

Table 2 shows the mass concentration of dust in the measurement section before and after spraying of four types of nozzles under different water pressures. From Table 2, the amount of dust generated by the aerosol generator in the experiment is basically stable and the mass concentration of dust in the measurement section before spraying is similar. It can also be seen from Table 2 that the mass concentration of dust in the measurement section after spraying is significantly lower than that before spraying, which proves that the spraying has a certain dust-reduction effect.

Figure 10 shows the distribution of particle size in the measurement section before spraying. From Fig. 10, since the specifications of the dust used in the experiment are the same, the particle size composition of the dust before

Table 2 Mass concentration of dust in the measurement section of four types of nozzles with different water pressures

\begin{tabular}{lllll}
\hline$p(\mathrm{MPa})$ & $\begin{array}{l}\text { Nozzle } \\
\text { number }\end{array}$ & Type & \multicolumn{2}{l}{$c_{\mathrm{mt}}\left(\mathrm{mg} / \mathrm{m}^{3}\right)$} \\
\cline { 3 - 5 } & & & $\begin{array}{l}\text { Before } \\
\text { spraying }\end{array}$ & $\begin{array}{l}\text { After } \\
\text { spraying }\end{array}$ \\
\hline 2.0 & 1 & Tangential flow-guide & 337.43 & 77.34 \\
& 2 & X-swirl nozzle & 347.56 & 58.81 \\
& 3 & Spiral porous & 354.50 & 80.61 \\
& 4 & Spiral non-porous & 360.51 & 69.97 \\
4.0 & 1 & Tangential flow-guide & 324.46 & 53.31 \\
& 2 & X-swirl nozzle & 342.94 & 45.78 \\
& 3 & Spiral porous & 291.30 & 57.27 \\
& 4 & Spiral non-porous & 326.56 & 59.86 \\
& 1 & Tangential flow-guide & 331.27 & 41.81 \\
& 2 & X-swirl nozzle & 324.62 & 39.05 \\
& 3 & Spiral porous & 373.10 & 46.08 \\
& 4 & Spiral non-porous & 351.54 & 47.53 \\
\hline
\end{tabular}

spraying is basically the same under different working conditions and the pattern of the particle size distribution is similar. From the cumulative volume curve in Fig. 10, it can also be seen that the proportion of respirable dust in the coal powder used in the experiment is about $20 \%$.

Figure 11 shows the distribution of dust particle size in the measurement section after spraying. Although the particle size distribution of the dust before spraying is similar under different working conditions, there is a significant difference in the particle size distribution of the dust after spraying, which is mainly caused by the difference in the dust-reduction efficiency of the spraying under each working condition. For the same nozzle, the particle size distribution of the dust varies under different water supply pressures. In general, as the water pressure increases, the dips of the volume frequency in the size distribution curve after spraying moves toward the left, i.e., toward the direction in which the particle diameter decreases. The position of the dips represents the particle diameter with high classification efficiency. As the water pressure increases, the droplet size decreases while the classification efficiency of the small dust particle increases correspondingly, causing the dips of the volume frequency to move toward the left. It can also be seen from Fig. 11 that under the same water pressure, the particle size distribution of the dust after spraying is different for the four different nozzles. The difference in the particle size distribution is mainly caused by the difference in the dust-reduction performance of the four types of nozzles.

\subsection{Dust-reduction efficiency by spraying}

According to the dust mass concentration in the measurement section before and after spraying in Table 2, the dustreduction efficiency by spraying can be calculated under each working condition. The calculated dust-reduction efficiency by spraying is the dust-reduction efficiency for the total dust. At the same time, the proportion of respirable dust in the measurement section before and after spraying under various working conditions can be obtained from the measurement results of the particle size distribution. Combing the proportion of respirable dust with the dustreduction efficiency for the total dust, the dust-reduction efficiency for the respirable dust can also be obtained. The dust-reduction efficiency for both total dust and respirable dust of the four types of nozzles under different water pressures can be obtained, as shown in Fig. 12.

Comparing the data of dust-reduction efficiency by spraying in Fig. 12, it is found that the dust-reduction efficiency of the same nozzle increases with the increase of the water pressure; however, when the water pressure reaches $4.0 \mathrm{MPa}$, there is no significant change of the dustreduction efficiency with the increase of the water pressure. 

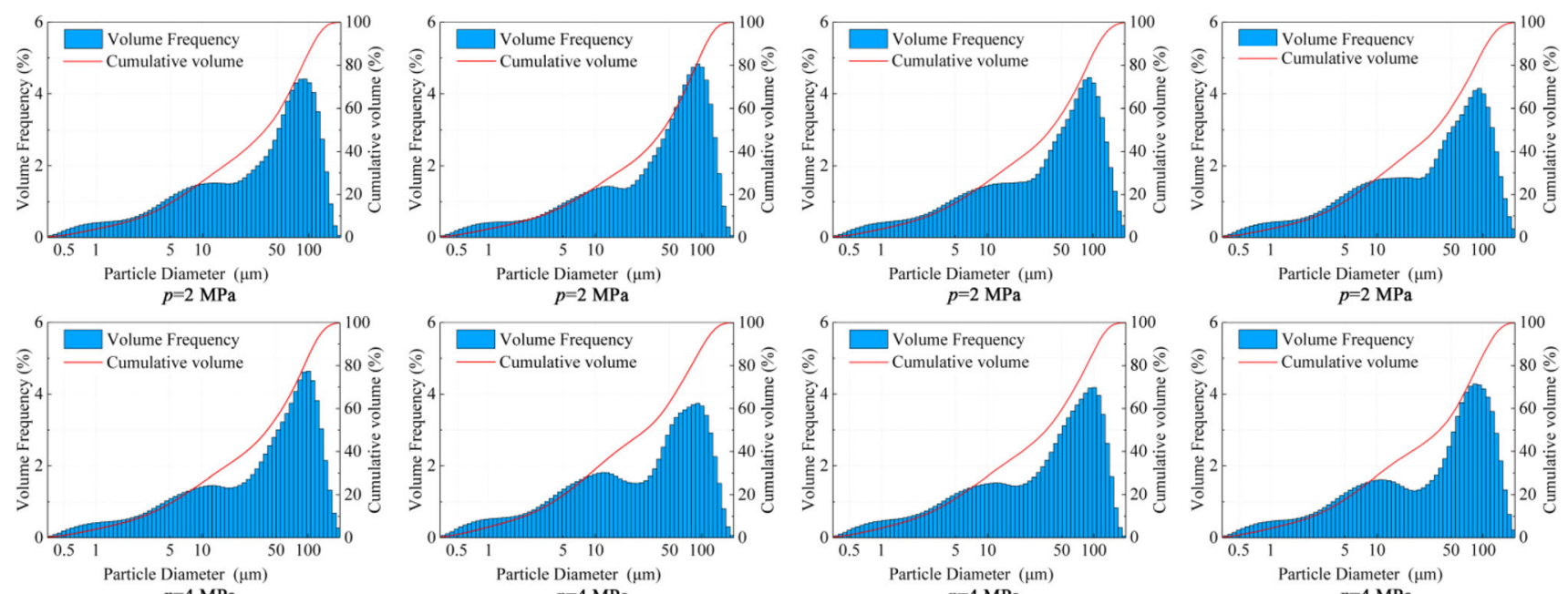

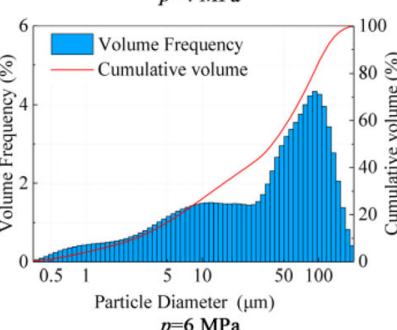

(a)

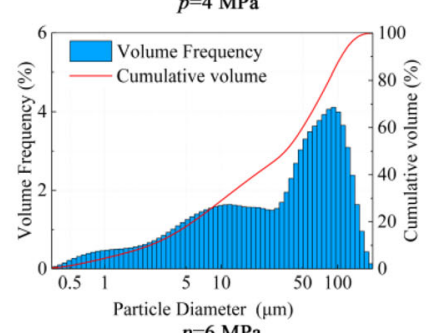

(b)

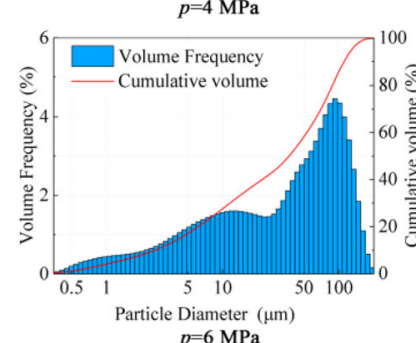

(c)

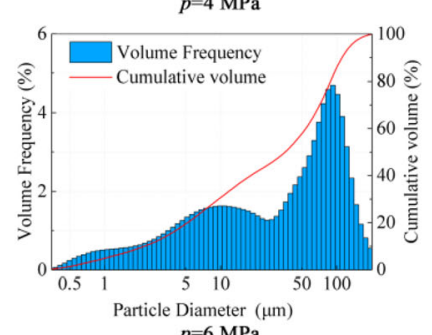

(d)

Fig. 10 Particle size distribution of dust before spraying. a Tangential flow-guide; b X-swirl; c Spiral porous; and d Spiral non-porous
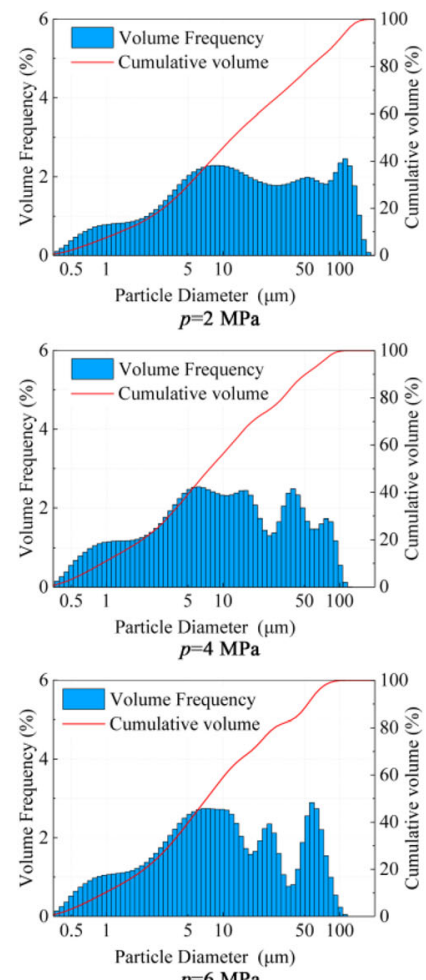

(a)
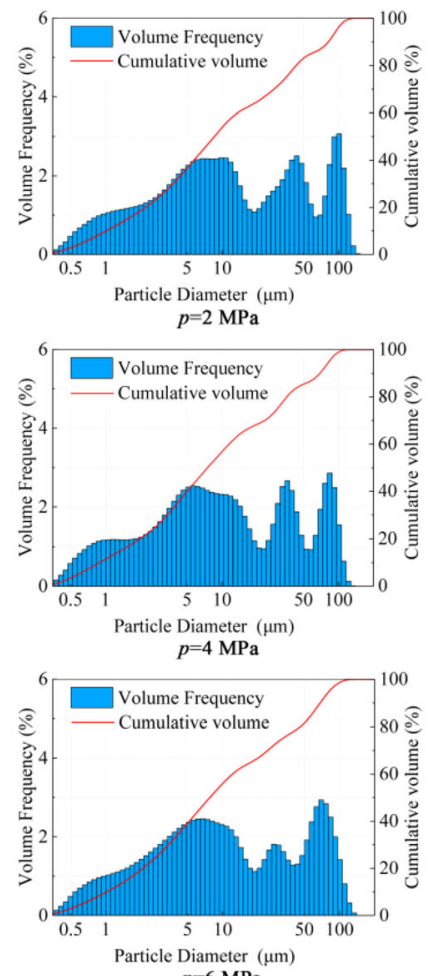

(b)

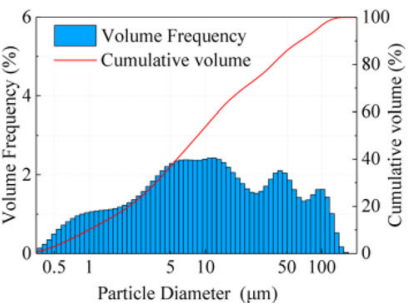

$p=2 \mathrm{MPa}$
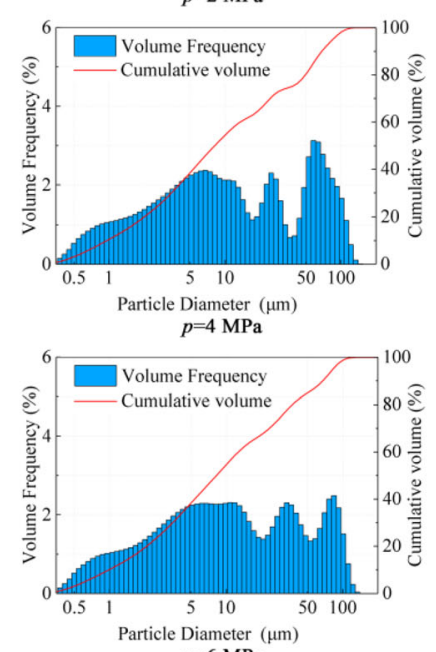

(c)

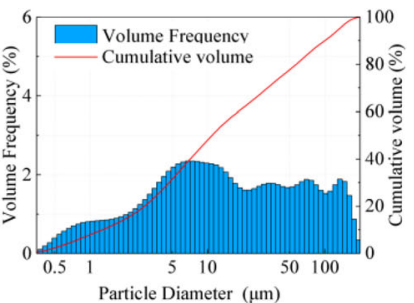

$p=2 \mathrm{MPa}$
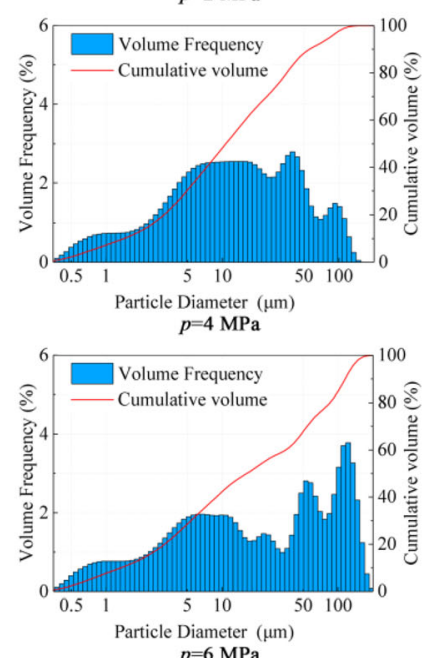

(d)

Fig. 11 Particle size distribution of dust after spraying. a Tangential flow-guide; b X-swirl; c Spiral porous; and d Spiral non-porous 

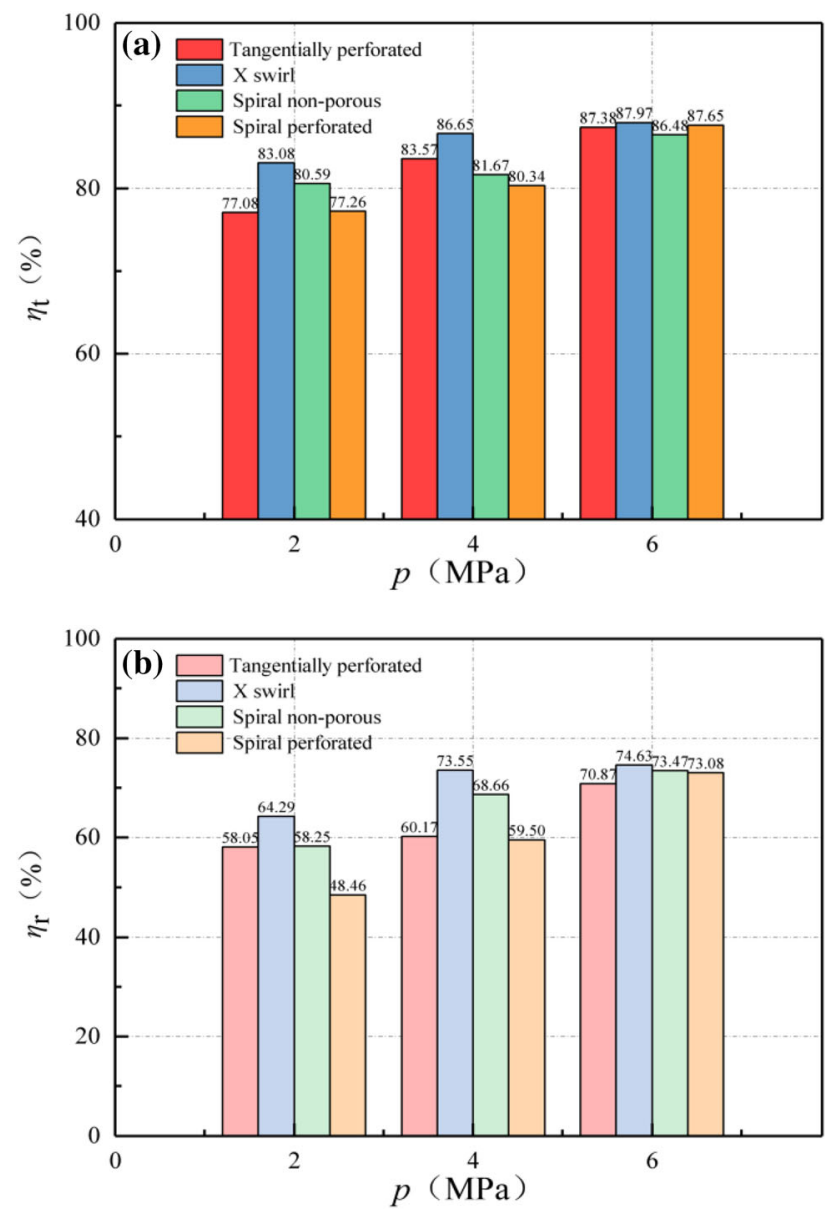

Fig. 12 Dust reduction efficiency of four spray nozzles. a Total dust; and $\mathbf{b}$ Respirable dust

In addition, as the water pressure increases, the dust-reduction efficiency for the respirable dust is more obviously changed than that for the total dust. With the increase of water pressure, the water flow rate of the nozzle is continuously increased and the volume concentration of the droplets in the roadway is increased, thus the possibility of droplet-dust collision and suppression is improved. Meanwhile, the increase in water pressure can increase the droplet velocity and reduce the droplet size, which are beneficial for the dust-reduction efficiency, especially for respiratory dust. When the water pressure increases to a certain value, the corresponding volume concentration of the droplets in the roadway is large enough while the particle size of the droplets is reduced slightly. As a result, the dust-reduction efficiency for both the total dust and the respirable dust does not have much increase as the water pressure changes.

Also shown in Fig. 12, when the water pressure is low $(p=2.0 \mathrm{MPa})$, the X-swirl nozzle has the highest dustreduction efficiency for both the total dust and the respirable dust due to the large flow coefficient, which is only slightly lower than that of the spiral porous nozzle. At the same time, under the water pressure of $2.0 \mathrm{MPa}$, the $\mathrm{X}$-swirl nozzle has a smaller droplet size and a higher droplet velocity. Under the impacts of the above factors, the X-swirl nozzle has the highest dust-reduction efficiency for both the total dust and the respirable dust among the four types of nozzles. Although the spiral porous nozzle has the highest flow coefficient, the droplet size is significantly larger than that of the other three under the water pressure of 2.0 MPa, resulting in low dust-reduction efficiency, especially a much lower dust-efficiency for the respirable dust than the other three types of nozzles. Although the spiral non-porous nozzle has the smallest particle size, the flow rate and droplet velocity are not superior. As a result, the dust-reduction efficiency of the spiral non-porous nozzle is in the second place. Therefore, in the coal mine application site, if the water pressure of the pipe network for dust reduction is limited, the spiral porous nozzle should be avoided to be selected due to the unguaranteed dust-reduction efficiency and a large amount of water consumption. In the view of dust-reduction efficiency, the X-swirl nozzle is preferred because high dustreduction efficiency for both the total dust and the respirable dust can be obtained under the same water pressure.

From Fig. 12, it can also be seen that with the increase of water pressure, the dust-reduction efficiency of the four types of nozzles is getting more and more similar. For example, when $p=6.0 \mathrm{MPa}$, the difference in the dustreduction efficiency of the four types of nozzles is less than $2 \%$ for the total dust and less than $4 \%$ for the respirable dust. When the water pressure is increased to a certain value, the volume concentration of the droplets in the roadway is sufficiently large for all the four types of nozzles, resulting in very similar dust-reduction efficiency for the total dust. At the same time, there are some differences in the dust-reduction efficiency for the respirable dust due to the difference in droplet size and droplet velocity. Comparing the two types of spiral channel nozzles, the dust-reduction efficiency of the non-porous type is higher than that of the porous type when the water pressure is low. Although the porous nozzle has advantageous flow rate, the droplet size of the porous nozzle is much larger than that of non-porous nozzle at the low water pressure, resulting in lower dust-reduction efficiency than non-porous type, especially for the respirable dust. With the increase of water pressure, the droplet size of both types of nozzles is relatively similar. Meanwhile, the porous nozzle has higher water flow rate and droplet velocity than the non-porous nozzle. As a result, when the water pressure reaches 6.0 MPa, the dust-reduction efficiency of the porous nozzle is slightly higher than that of the non-porous nozzle. In order to evaluate the dust-reduction performance and economic benefits of the four types of nozzles under high 


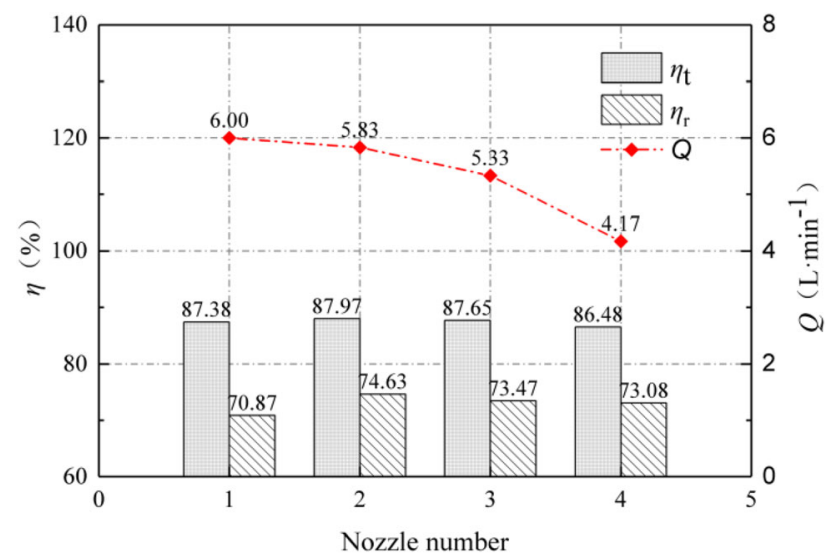

Fig. 13 Dust reduction efficiency and water flow rate of the four types of nozzles

water pressure, the dust reduction efficiency and water flow rate of the four types of nozzles at the water pressure of 6.0 MPa are plotted and shown in Fig. 13.

From Fig. 13, when the water pressure is $6.0 \mathrm{MPa}$, the dust-reduction efficiency for both total dust and respirable dust is similar for all the four types of nozzles. However, there is a significant difference in the water flow rates of these four types of nozzles. Among them, the spiral nonporous nozzle has the smallest flow rate of $4.17 \mathrm{~L} / \mathrm{min}$, and water flow rates of the other three types of nozzles are higher than $5.0 \mathrm{~L} / \mathrm{min}$. From the above analysis, it can be found that when the water pressure is high, there is no significant difference in dust-reduction efficiency among the four types of nozzles, but the spiral non-porous nozzles consume much less water than the other three types of nozzles thus has obvious economic advantage. Therefore, based on comprehensive considerations, a spiral non-porous nozzle is recommended when the water pressure is high. Of course, as previously analyzed, the atomization angle and range of the four types of nozzles are different. Therefore, the selection of nozzles should be based on the on-site working conditions and multiple factors such as range and atomization angle should be taken into account to design the most reasonable spraying scheme for dust reduction.

\section{Conclusions}

In this study, four types of commonly used nozzles in coal mine underground with different internal structures were selected, and the atomization characteristics of the four types of nozzles were investigated and compared using Malvern droplet size analyzer, PIV system and flow measurement instrument. On this basis, the dust-reduction performance of four types of nozzles under different water pressures was studied using the custom-developed dustreduction experimental platform by spraying. The following conclusions can be obtained:

(1) Among the four types of nozzles, both types of spiral channel nozzles have relatively small flow coefficient. In addition, the flow coefficient of the spiral non-porous type is the smallest among all four types of nozzles. The flow coefficients of the tangential flow-guided nozzle and the $\mathrm{X}$-swirl nozzle are higher and similar to each other.

(2) The atomization angles of all the four types of nozzles first increased and then decreased with the increase of water pressure. Under the same water pressure, the atomization angle of the spiral nonporous nozzle is the largest, and the change of the atomization angle is not obvious with the increase of the water pressure. The X-swirl nozzle and the spiral porous nozzle have smaller atomization angles. The range of the nozzle is inversely proportional to the atomization angle, thus the nozzle with a larger atomization angle has a relatively smaller range.

(3) When the water pressure is low $(p<3 \mathrm{MPa})$, the atomization performance of the spiral non-porous nozzle is the best among the four types of nozzles. However, in the high water pressure zone, the change in the droplet size of the spiral non-porous nozzle is not obvious with the increase of the water pressure and the droplet size is significantly higher than that of the other three types of nozzles. The $\mathrm{X}$-swirl nozzle shows advantages in the atomization performance under the high water pressure. Under the same water pressure, the smallest droplet size can be obtained in the X-swirl nozzle.

(4) When the nozzle has a small atomization angle, the droplet flow is concentrated and the attenuation of the droplet velocity is relatively, resulting in a high droplet velocity in the downstream of the nozzle. Among the four types of nozzles, the spiral nonporous nozzle has the smallest flow coefficient and the largest atomization angle, thus the downstream droplet velocity of the spiral non-porous nozzle is smallest. The droplet velocity of the other three types of nozzles is in the following order: spiral porous nozzle $>\mathrm{X}$-swirl nozzle $>$ tangential flowguide nozzle.

(5) With the increase of water pressure, the dustreduction efficiency of the four types of nozzles for both total dust and respirable dust are getting similar. When the water pressure reaches $6 \mathrm{MPa}$, there is no significant difference in the dust-reduction efficiency among the four types of nozzles, but there is a significant difference in the water flow rates among 
them. Based on the comprehensive consideration. In the coal mine application site, it is recommended to use the spiral non-porous nozzle under high water pressure. If the water pressure for dust reduction is low, the X-swirl nozzle is recommended based on the consideration of the dust-reduction efficiency.

Acknowledgements Financial support for this work, provided by the National Natural Science Foundation of China (No. 51574123), the Hunan Provincial Natural Science Foundation of China (No. 2017JJ3076) and Hunan Graduate Research and Innovation Project (No. CX2018B661), are gratefully acknowledged.

Author contributions Data curation, HH and CT; formal analysis, $\mathrm{HH}$ and CT; funding acquisition, PW and RL; methodology, PW; project administration, $\mathrm{PW}$; resources, $\mathrm{HH}$; supervision, RL; writing — original draft, $\mathrm{HH}$; writing — review and editing, PW and RL.

\section{Compliance with ethical standards}

Conflict of interest The authors declare no conflict of interest.

Ethical standards The experiments comply with the current laws of the country in which they were performed.

Open Access This article is licensed under a Creative Commons Attribution 4.0 International License, which permits use, sharing, adaptation, distribution and reproduction in any medium or format, as long as you give appropriate credit to the original author(s) and the source, provide a link to the Creative Commons licence, and indicate if changes were made. The images or other third party material in this article are included in the article's Creative Commons licence, unless indicated otherwise in a credit line to the material. If material is not included in the article's Creative Commons licence and your intended use is not permitted by statutory regulation or exceeds the permitted use, you will need to obtain permission directly from the copyright holder. To view a copy of this licence, visit http://creativecommons. org/licenses/by/4.0/.

\section{References}

Chen X, Ge SC (2013) Numerical simulation of high-pressure spray coal dust capture technology based on Fluent software and its application. Soc Saf Sci J 23:144-149

Cheng WM, Zhou G, Zuo QM, Nie W, Wang G (2010) Experimental study on the relationship between nozzle spray pressure and atomization particle size. J China Coal Soc 35:1308-1313

Cheng WM, Nie W, Zhou G, Zuo QM (2011) Study of dust suppression by atomized water from high-pressure sprays in mines. J China Univ Min Technol 40:185-190

Couto HS, Carvalho JA, Bastos-Netto D (1997) Theoretical formulation for sauter mean diameter of pressure-swirl atomizers. J Propul Power 13:691-696

Dumouchel C (2009) The maximum entropy formalism and the prediction of liquid spray drop-size distribution. Entropy 11:713-747

Fan H, Yang G, Bing Li (2018) Numerical investigation on inner flow field of pressure swirl nozzle. J Mech Electr Eng 35:838-842

Harshad S, Arindrajit C, Prabhu SV (2020) Characterization of solidcone simplex mist nozzles. Fire Saf J 111:102936
Li X, Tankin RS (1992) On the prediction of droplet size and velocity distributions in sprays through maximum entropy principle. Part Part Syst Charact 9:195-201

Luo Y, Wang DM, Cheng JW (2017) Effects of rock dusting in preventing and reducing intensity of coalmine explosions. Int $\mathbf{J}$ Coal Sci Technol 4(2):102-109

Ma SP, Kou ZM (2005) Study of mechanism of reducing dust by spray. J China Coal Soc 30:297-300

Ma SP, Kou ZM (2006) Study of efficiency of dust suppression by mist spray and its matched parameters. China Saf Sci J 16:84-89

Nie W, Peng HT, Jin H, Liu YH, Wei WL (2017) The effect of spray pressure on atomization characteristics of external spray nozzle on coal mining machine. J China Univ Min Technol 46:41-47

Reed WR, Zheng Y, Yekich M, Ross G, Salem A (2018) Laboratory testing of a shuttle car canopy air curtain for respirable coal mine dust control. Int J Coal Sci Technol 5(3):305-314

Sellens RW (1989) Prediction of the drop size and velocity distribution in a spray, based on the maximum entropy formalism. Part Part Syst Charact 6:17-27

Seoksu M, Essam AS, Choongsik B (2008) Thespray characteristics of a pressure-swirl injector with various exit plane tilts. J Int J Multiph Flow 34:615-627

Seoksu M, Essam AS, Choongsik B (2009) Air flow and pressure inside a pressure-swirl spray and their effects on spray development. Exp Therm Fluid Sci 33:222-231

Tawatchi C, Wiwut T (2011) Deterministic model of open-space dust removal system using water spray nozzle: effects of polydispersity of water droplet and dust particle. Sep Purif Technol 77:382-388

Wang XF, Lefebvre AH (1987) Mean drop sizes from pressure-swirl nozzles. J Propul Power 3:11-21

Wang PF, Liu RH, Tang M, Zhang W, Gui Z (2015) Experimental research on relationship between dust suppression efficiency and nozzle diameter. China Saf Sci J 25:114-120

Wang PF, Tan XH, Cheng WM, Guo G, Liu RH (2018a) Dust removal efficiency of high pressure atomization in underground coal mine. J Int J Min Sci Technol 28:685-690

Wang H, Nie W, Cheng WM, Liu Q, Jin H (2018b) Effects of air volume ratio parameters on air curtain dust suppression in a rock tunnel's fully-mechanized working face. Adv Powder Technol 29:230-244

Wang PF, Li YJ, Liu RH, Shi YJ (2019) Effect of forced-to-exhaust ratio of air volume on dust control of wall-attached swirling ventilation for mechanized excavation face. Tunn Undergr Space Technol 90:194-207

Wang PF, Han H, Liu RH, Gao RZ, Wu GG (2020) Effect of outlet diameter on atomization characteristics and dust reduction performance of X-swirl pressure nozzle. Process Saf Environ Prot 137:340-351

Yang SB, Nie W, Lv SS, Liu ZQ, Peng HT, Ma X, Cai P, Xu CW (2019) Effects of spraying and installation angle of nozzles on atomization characteristics of external spraying system at a fullymechanized mining face. Powder Technol 343:754-764

Yi BB, Liu RH, Wang PF, Gou SX, Tan XH, Zhang K (2018) Experimental study on atomization angle of X-type swirl pressure nozzle. Min Technol 18:71-75

Yu HM, Cheng WM, Peng HT, Xie Y (2018) An investigation of the nozzle's atomization dust suppression rules in a fully-mechanized excavation face based on the airflow-droplet-dust threephase coupling model. Adv Powder Technol 29:941-956

Zhang Q, Zhou G, Qian XM, Yuan MQ, Sun YL, Wang D (2018) Diffuse pollution characteristics of respirable dust in fullymechanized mining face under various velocities based on CFD investigation. J Clean Prod 184:239-250 
Zhao JG, He W (2017) Simulation and experimental research on highly efficient atomization nozzle with a core. Mach Des Manuf 55:137-140

Zhou G, Cheng WM, Nie W, Wang G (2012) Extended theoretical analysis of jet and atomization under high-pressure spraying and collection dust mechanism of droplet. J Chongqing Univ $35: 121-126$

Zhou G, Zhang Q, Bai R, Fan T, Wang G (2017) The diffusion behavior law of respirable dust at fully mechanized caving face in coal mine: CFD numerical simulation and engineering application. Process Saf Environ Prot 106:117-128 